The Aye Aye

I FIRST saw the quotation from the Pall Mall Gazelte in the columns of NATURE concerning the long finger nail of the Aye Aye, and the "exquisite argument" founded by Professor Owen upon it.

As a simple matter of fact, allow me to state that I kept a Iiving A ye Aye (now preserved in the British Museum) in a large cage in the Mauritius, and as its food I gave it the maggot that infested branches of a species of Acacia. The animal used to spend its evenings in feeding, as follows. It listened attentively at the branches, tapping occasionally the most perforated parts; it then tore off pieces of the wood around the maggot hole, inserting the peculiar long finger as a probe from time to time, and ended by extracting the maggot by means of this long finger and its strong rodent teeth.

I have seen the operation scores of times.

Athenæum, May 28 HuMPhRY SANDWITH

\section{Carp and Toads}

IN the last number of NATURE you give an abstract of a paper by $M$. Duchemin on the destruction of carp by toads. The fact that carp are so destroyed is, or was, well known. Walton, in his "Complete Angler," says :- "And I have known of one (person) that lias almost watched the pond, and at the fishing of the pond, found of seventy or eighty large carps not above five or six; and that he had foreborne longer to fish the said pond, but that he saw on a hot day in summer, a large carp swim near the top of the water with a frog upon his head; and that he, upon that occasion, caused his pond to be let dry; and I say, of seventy or eighty carps, only found five or six in the said pond, and those very sick and lean, and with every one a frog sticking so fast on the head of the said carps, that the frog would not be got oft without extreme force or killing." Walton also mentions that pike are attacked and destroyed in the same manner. Walton wrote his " Complete Angler, or Contemplative Man's Recreation" in 1653. The confusion between frogs and toads was one likely to be made at a time when natural history was so little studied. In all other respects Walton's account agrees with M. Duchemin's.

C. H. G.

\section{Anticipated Destruction of the Cheesewring}

I AM sure your readers will pardon me for drawing their attention to the very perilous situation of that remarkable pile of rocks, six or seven miles north of the town of Liskeard, in Cornwall, and known as the Wring-cheese or Cheesewring. Wilkie Collins, in his "Rambles beyond Railways," thus describes the general appearance of this natural curiosity :--.- "If a man dreamt of a great pile of stones in a nightmare, he would dream of such a pile as the Cheesewring. All the heaviest and largest of the seven thick slabs of which it is composed are at the top; all the lightest and smallest at the bottom. It rises perpendicularly to a height of thirty-two feet, without lateral support of any kind. The fifth and six rocks are of immense size and thickness, and overhang fearfully all round the four lower rocks which support them. All are perfectly irregular; the projections of one do not fit into the interstices of another; they are heaped up loosely in their extraordinary top-heavy form on slanting ground, half way down a steep hill." Of late years this hill has been so extensively quarried for granite that the workmen are now within a few paces of the Cheesewring itself. When a lease of the ground was first granted, it was stipulated that no stone should be removed within a certain distance of this well-known landmark, so as to prevent any possibility of its being destroyed. Now, however, the boundaries of the quarry have been so extended that powerful blasting operations are continually being carried on within a short distance of it, not without very great risk to the whole structure. In fact, it is on the eve of being destroyed, unless a vigorous and influential attempt is made to save it. Six months ago the Royal Institution of Cornwall sent a deputation of its members to report on the exact state of the Cheesewring; and although a memorial was addressed to the anthorities of the Duchy of Cornwall, the owners of the property, praying that some means be adopted for the preservation of this extraorclinary geological formation, no satisfactory reply has been hitherto received. Since, therefore, local influence appears to be of little or no avail, it is to be hoped that the matter will be taken up by those who are especially interested in the preserva. tion of remarkable objects of this kind. The untimely fate of the great Tolmên last year should be remembered ; and measures immediately adopted to avoid a repetition of a similar catastrophe within so short a period. Whatever is done should be begun speedily, or in the meantime the impending calamity may actually take place.

Greenwich

E. H. W. DUNKIN

\section{Left-handednæss}

I HAD been intending, if no one had anticipated me, to suggest what I have little doubt is the true explanation of the destruction of carp by toads. I see in p. 59 of NATURE for May 19, that Mr. Wade hints at this solution of the difficulty.

Let me take this opportunity of saying a word on Left-handedness. The late eminent anatomist, Professor Gratiolet, maintained that in the early stages of foetal development, the anterior and middle lobes of the brain on the left side were in a more advanced condition than those on the right side, the balance being maintained by an opposite condition of the posterior lobes. Hence, in consequence of the well-known decussation of the nerve-ronts, the right side of the body-5o far as it is influenced by brain force--would, in early fœtal life, be better supplied with nervous power than the left side; and movements of the right arm would precede and be more perfect than those of the left. If Gratiolet's view is regarded as established (it has, I believe, been disputed), we have a physiological clue to the explanation of Right-handedness. In rare cases the development of the interior and middle lobes of the right side may precede that of the left ; we shall then have Left-handedness.

May 2 I

M.A., CANT,

IN answer to Mr. Meyer's letter on this subject, I can only say that the question of the dependence of Left-handedness on abnormality of the subclavian artery cannot be settled by the authe. rity of even so eminent an anatomist as Professor Hyrtl, when it is adduced against the facts I mentioned in my last note. That there have been cases like that quoted from Dr. Buchanan of transposition of viscera and left-handedness occurring in the same individual, and that they will be observed again, I do not doubt. Otherwise the conclusion would be that such abnormalities prevent left-handedness, which no one pretends. What I venture to think the cases already on record prove is, that the one condition has no relation to the other in either causing or preventing it.

With regard to the origin of the right subclavian direct from the end of the transverse aorta, though I have met with several cases of this variation, they were in subjects whose history was unknown; while, unlike complete transposition of the viscera, the condition cannot of course be recognised during life. But at the last meeting of the Pathological Society, a case of aneurism with this abnormality was brought forward; and, by the kindness of Dr. Peacock, who exhibited it, $I$ am informed that the patient was undoubtedly right-handed during life.

Even apart from facts like this, one would scarcely expect to find the explanation of left-handedness in abnormalities affecting only the upper extremity. The condition is one of the eye, the leg, and the whole body. This one discovers in using the microscope, shooting, and batting; and the facts of aphasia appear to show that we are all, to use M. Broca's phrase, gauchers de cerveau. In fact, we must first explain normal right-handedness, and that not only as seen in man, but also in the paces of the horse, and in many other alternate or otherwise unsymmetrical movements of animals.

The only anatomical explanation of right-handedness I have met with is the unconfirmed statement of Gratiolet that the left half of the brain is developed more rapidly than the right. But even if true, this would only throw back the question to the origin of such a condition of the brain.

That the primitive habit of bilaterally symmetrical animals is to use right and left organs equally, seems probable, and also that when more complicated movements have to be performed, one limb alone must be chosen and so in time become more skilful. This preference may be transmitted hereditarily. But, granting in addition that the convenience of the community requires that all its members should select the same limb, it yet is not clear by what process of natural selection the right one has come to be universally preferred to the left-how, in fact, except from practice, right-handedness has come to be dexterity, and left-handedness gaucherie. 